Ciência e Natura, v. 37 Part 2 2015, p. 276-284

ISSN impressa: 0100-8307 ISSN on-line: 2179-460X ciênciaenatura

\title{
STATCOM Control based on Indirect Adaptive Sliding Mode Controller for Compensation of Reactive Power
}

Seyed Hasan Mosavi ${ }^{1}$, Ali Kalantarzade ${ }^{2}$, Moslem Dehghani ${ }^{3}$, Leila Eilan Kashkoli, Hossein Moafian ${ }^{5}$

1,2,3,4,5 Electrical Engineering Department, M.S. of Islamic Azad University, Kazeroon Branch, Iran

\begin{abstract}
In this paper, an indirect adaptive sliding mode controller has been designed to control distribution static compensator to improve power quality in a three-phase distribution network. Steady-state error flow control compensator is reduced using the proposed controller. The proposed control strategy is more resistant compared to disturbances in the transient and steady state. The controller is used in frame of $B_{\alpha}$ rotating reference. Using an observer for estimating parameters, the controller performance has been improved. The accuracy of controller performance has been proven in the software package of MATLAB.
\end{abstract}

Keywords: Reactive Power Compensation, Adaptive Sliding Mode Controller, DSTATCOM, Observer. 


\section{Introduction}

Among the main challenges associated with electric power distribution networks can be pointed to the issue of quality. Problems of voltage, current and frequency, followed by misbehaving electrical equipment are proposed as the power quality problems as well as a lack of voltage and voltage flicker [1]. Some of these problems can be pointed to the lack of voltage and voltage flicker. These phenomenon are the most important issues of induction motors startup that are included almost $80 \%$ of power quality problems in power distribution networks. Based on the IEEE 1159-1995 standard, voltage shortage is a reduction between 0.1 to $0.9 \mathrm{pu}$ in the amount of effective voltage with power frequency for a time of a half cycle to one minute. Different reasons can be cited for the occurrence of this phenomenon. Some of the main reasons of that can be pointed to the errors types of short circuit, large induction motors startup, sudden load changes and transferring energy to transformer leading to transformer inrush current [2]. According to the IEC 61000-4-15 standard, voltage fluctuations in the frequency range of 1 to 35 $\mathrm{Hz}$ can produce voltage flicker [3]. Some of sources of flicker generation are electric arc furnace, metallurgical machinery, wind turbines, generators producing electricity from sea waves, induction motors startup and frequency converters. This phenomenon can cause eye irritation as a human factor as well as interfere in sensitive electrical equipment such as medical and telecommunications devices as an industry factor [2]. Due to the use of sensitive equipment in modern industrial projects such as control process, PLC, speed adjusting drives and robots, other phenomena of voltage shortage and voltage flicker in power distribution networks are not tolerated and various ways have been used to reduce it.

Conventional methods in this context involve the use of capacitor banks, construction of new parallel feeders and installation of un-interrupted power supplies (UPS), but in recent years using the compensator based on current and voltage source converters has been considered by power industry experts due to the development of the semiconductor industry. These equipment namely Flexible Alternating Current Transmission System (FACTS) can compensate rapidly and controllable [4]. Set of FACTS devices that are used in distributed systems to improve power quality are called D-FACTS devices or custom power [5].

Distribution static synchronous compensator (DSTATCOM) is one of the most important devices of a distributed flexible alternating current transmission system (DFACTS). With an appropriate control strategy, DSTATCOM can have features such as reactive power compensation, harmonic filtering and eliminating voltage fluctuations and flicker [6] and [7]. DSTATCOM control method usually uses direct power control by injecting a current with a constant amplitude and positive direction with respect to the current compensation for reactive power compensating and harmonics filtering. Control strategy of DSTATCOM is usually based on PI controller combined with pulse width modulation. This traditional controller has many disadvantages such as the need for complex hardware, large error and slow response, so an accurate compensation is obtained too difficult.

The second major changes in error is because of constant frequency of power electronic equipment [7]. In this paper, an indirect adaptive integral sliding mode variable structure controller method based on the coordinate system $\beta \alpha$ has been used for DSTATCOM, which is a fast reactive power compensation and is followed by harmonic filtering. This method reduces the number of controllers compared with the methods used to control the variable structure of DSTATCOM, and it is compatible with the 
system parameters [9-7]. Adaptation of controller to unknown parameters of the system increases the resistance of the controller.

Sliding mode control based on variable structure control compared to traditional control method has several advantages, including robustness under parameter variations and external disturbances as well as good and fast dynamic response [10]. Adaptation of controller to the system work point changes and disturbances causes to improve the accuracy and performance of the controller, and steady-state error becomes closer to zero.

Control algorithms including synchronous reference frame theory (SRFT), instantaneous reactive power theory (IRPT), ADALINE algorithm [11], instantaneous symmetrical component theory (ISCT), I $\cos \varnothing$ algorithm [12], power balance theory (PBT) algorithm, control algorithms based on neural networks and fuzzy logic to correct the power factor, voltage adjustment, balancing charge and harmonic elimination have been used.

Most of the control algorithms are used the measured load current to estimate the reference current of source. Various control algorithms with different topologies have been proposed to control DSTATCOM [13-11] that reduce supply current sensors, load currents, point of common coupling (PCC) voltages and DC link voltage as well as feedback signals for the dynamic performance of DSTATCOM. The advantages of using the sliding mode controller (SMC) is estimating the reference current through the DC link voltage of variable structure control (VSC) used for DSTATCOM. Another advantage of SMC is regulation of DC link voltage. The DC link voltage changes under disturbances such as load changes in the SMC controller is negligible compared with PI controller [1413]. In the sliding mode control, compensation currents of DSTATCOM are controlled to follow the reference value. SMC control algorithm detects deviations from the reference value and immediately changes switching strategy to follow the reference path [19-13]. SMC controller shows a robust performance under change of parameters. In [13], the importance and benefits of SMC controllers compared with PI controller have been described and clearly modeled.

In this paper, an indirect adaptive sliding mode controller has been used to control DSTATCOM that the proposed observer estimates the system's parameters. This article is classified as following: In section (2), configuration of a DSTATCOM with the dynamic of the system has been provided in the form of rotating dq. In section (3), designing of the observer, the sliding mode controller and stability analysis have been investigated. In section (4), Simulation results under different conditions such as nonlinear loads has been provided. At the end, final conclusion has been presented in section (5).

\section{DSTATCOM Model}

DSTATCOM main circuit has been shown in Figure 1 [20-21]. Equation (1) shows the model of the state of the system where $\mathrm{L}$ is the inductance between the inverter and PCC, $\mathrm{R}$ is the resistance of inverter losses, us is the equipment connection point voltage and ut shows the inverter output voltage.

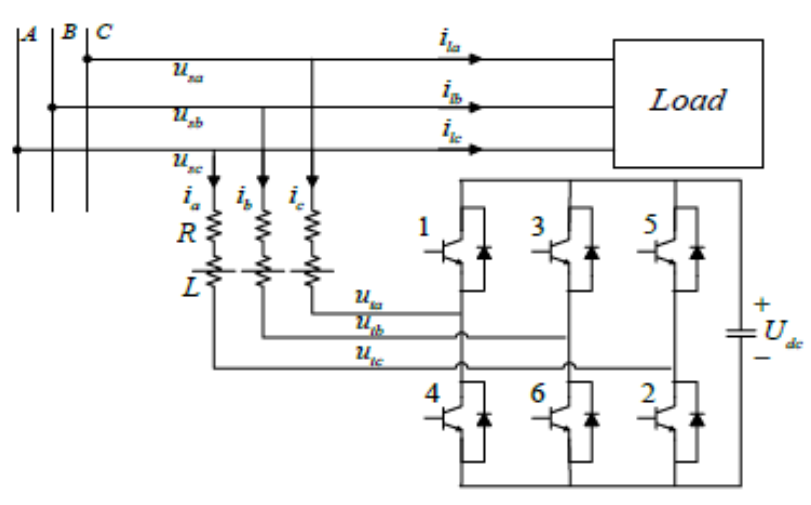

Figure (1): DSTATCOM main circuit 


$$
\left\{\begin{array}{l}
\mathrm{L} \frac{\mathrm{d}}{\mathrm{dt}} \mathrm{i}_{\mathrm{a}}+\mathrm{Ri}_{\mathrm{a}}=\mathrm{u}_{\mathrm{ga}}-\mathrm{u}_{\mathrm{ta}} \\
\mathrm{L} \frac{\mathrm{d}}{\mathrm{dt}} \mathrm{i}_{\mathrm{b}}+\mathrm{Ri}_{\mathrm{b}}=\mathrm{u}_{\mathrm{sb}}-\mathrm{u}_{\mathrm{tb}} \\
\mathrm{L} \frac{\mathrm{d}}{\mathrm{dt}} \mathrm{i}_{\mathrm{c}}+\mathrm{Ri}_{\mathrm{c}}=\mathrm{u}_{\mathrm{sc}}-\mathrm{u}_{\mathrm{tc}}
\end{array}\right.
$$

In order to achieve a quick and accurate control for DSTATCOM, an indirect adaptive control method has been used in this article. Axis component references of $\mathrm{dq}$ are obtained from compensation of currents required for idref and iqref by using real-time detection of reactive and harmonic currents based on instantaneous reactive power theory [21]. By converting the $\alpha \beta$ rotating coordinate system, above references are used as VSC integral input. VSC integral outputs are ut $\alpha$.ref and ut $\beta$.ref. SVPWM method has been used to control turning on and turning off the inverter switching components. In general, DSTATCOM control is based on the state model in the $\mathrm{dq}$ rotating coordinate system [22]. Because of the combination of components $\mathrm{dq}$, the required separation trend increases the complexity of control. Control system strategy proposed in this paper is based on the state mode in $\alpha \beta$ rotating coordinate system that there is no combination between the components of two axis.

By converting equation (1) to $\alpha \beta$ coordinate system, the state equation is obtain as following:

$$
\left\{\begin{array}{l}
\mathrm{L} \frac{\mathrm{d}}{\mathrm{dt}} \mathrm{i}_{\alpha \mathrm{\alpha}}+\mathrm{Ri}_{\mathrm{\alpha}}=\mathrm{u}_{\mathrm{s \alpha}}-\mathrm{u}_{\mathrm{ta}} \\
\mathrm{L} \frac{\mathrm{d}}{\mathrm{dt}} \mathrm{i}_{\beta}+\mathrm{Ri}_{\beta}=\mathrm{u}_{\mathrm{s} \beta}-\mathrm{u}_{\mathrm{t} \beta}
\end{array}\right.
$$

where,

$$
\begin{aligned}
& {\left[\begin{array}{ll}
i_{\alpha} & i_{\beta}
\end{array}\right]^{r}=T_{a b c / a \beta}\left[\begin{array}{lll}
i_{a} & i_{b} & i_{c}
\end{array}\right]^{T}} \\
& {\left[\begin{array}{ll}
u_{s a} & u_{s \beta}
\end{array}\right]^{r}=T_{a b c / a \beta}\left[\begin{array}{lll}
u_{s a} & u_{s b} & u_{s c}
\end{array}\right]^{T}} \\
& {\left[\begin{array}{ll}
u_{t a \alpha} & u_{t \beta}
\end{array}\right]^{r}=T_{a b c / a \beta}\left[\begin{array}{lll}
u_{t a} & u_{t b} & u_{t c}
\end{array}\right]^{T}}
\end{aligned}
$$

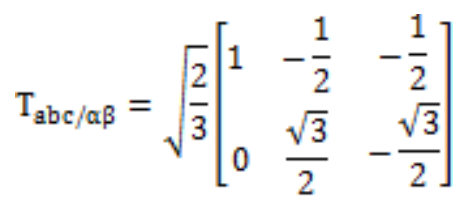

\section{Designing Observer, Sliding Mode Controller and Stability Analysis}

\subsection{Designing Observer}

Equation (1) is considered as a dynamic system. In current study, $\mathrm{R}$ and $\mathrm{U}_{\mathrm{dc}}$ are considered as system's uncertain parameters. it is assumed that $\mathrm{x}$ is available and measurable. However, an estimator has been used to facilitate designing the parameters adaptation roles for $\widehat{\mathrm{R}}$ and $\widehat{\mathrm{U}}_{\mathrm{dc}}$. Where, $\widehat{\mathrm{R}}$ and $\widehat{\mathrm{U}}_{\mathrm{dc}}$ are estimation parameters for $\mathrm{R}$ and $\mathrm{U}_{\mathrm{dc}}$, respectively. It is shown that $\widehat{\mathrm{R}} \rightarrow \mathrm{R}$ and $\widehat{\mathrm{U}}_{\mathrm{dc}} \rightarrow \mathrm{U}_{\mathrm{dc}}$. For this purpose, the following estimate has been considered.

$$
\begin{aligned}
& \mathrm{L} \frac{\mathrm{d}}{\mathrm{dt}} \mathrm{i}_{\mathrm{a}}+\mathrm{Ri}_{\mathrm{a}}=\mathrm{u}_{\mathrm{ga}}-\mathrm{u}_{\mathrm{ta}} \rightarrow \frac{\mathrm{d}}{\mathrm{dt}} \hat{\mathrm{X}}=-\frac{\widehat{\mathrm{R}}}{\widehat{\mathrm{L}}} \hat{\mathrm{X}}- \\
& \frac{1}{\mathrm{~L}} \mathrm{u}_{\mathrm{ta}}-\mathrm{K}(\mathrm{x}-\hat{\mathrm{X}})
\end{aligned}
$$

where, $\mathrm{k}$ defines as observer yield and $\hat{\mathrm{x}}$ is the value of $x$ estimation:

$$
\begin{aligned}
& \tilde{\mathrm{x}}=\mathrm{x}-\hat{\mathrm{x}} \rightarrow \hat{\mathrm{x}}=\mathrm{x}-\hat{\mathrm{x}} \\
& \mathrm{R}=\mathrm{R}-\widehat{\mathrm{R}} \rightarrow \hat{\mathrm{R}}=\mathrm{R}-\widehat{\mathrm{R}} \\
& \widetilde{\mathrm{U}}_{\mathrm{dc}}=\mathrm{U}_{\mathrm{dc}}-\widehat{\mathrm{U}}_{\mathrm{dc}} \rightarrow \quad \widehat{\mathrm{U}}_{\mathrm{dc}}=\mathrm{U}_{\mathrm{dc}}-\widetilde{\mathrm{U}}_{\mathrm{dc}}
\end{aligned}
$$

By substituting equation (4) into (3), equation (5) is retrieved:

$$
\frac{\mathrm{d}}{\mathrm{dt}} \widetilde{\mathrm{x}}=-\frac{\widetilde{\mathrm{R}}}{\mathrm{L}} \mathrm{x}-\frac{1}{\mathrm{~L}} \mathrm{u}_{\mathrm{ta}}-\mathrm{K} \tilde{\mathrm{x}}
$$

The following Lyapunov function is examined to create the adaptation role and analysis the stability:

$$
\begin{gathered}
V=\frac{1}{2} \mathrm{~L} \widetilde{\mathrm{X}}^{2}+\frac{1}{2 \beta_{1}} \mathbb{\mathrm { R }}^{2}+\frac{1}{2 \beta_{2}} \mathrm{U}_{\mathrm{dc}}^{2} ; \beta_{1}>0, \beta_{2}>0 \\
\hat{V}=\mathrm{LKX}+\frac{1}{\beta_{1}} \mathrm{R} \tilde{\mathrm{R}}+\frac{1}{\beta_{2}} \mathrm{U}_{\mathrm{dc}} \mathrm{U}_{\mathrm{dc}}<0
\end{gathered}
$$

By substituting equation (5) into (7), then we have: 
$\hat{V}=-K_{\mathrm{a}} \mathrm{L} \tilde{\mathrm{X}}^{2}+\left(-\mathrm{X} \tilde{\mathrm{x}}+\frac{1}{\beta_{1}} \hat{\mathrm{K}}\right) \tilde{\mathrm{K}}+\left(-\tilde{\mathrm{x}}+\frac{1}{\beta_{2}} \mathrm{U}_{\mathrm{dc}}\right) \mathbb{U}_{\mathrm{dc}}$

Since the parameter of $-\mathrm{K}_{\mathrm{a}} \mathrm{Lx}^{2}$ is a negative number, the parameters in parentheses must be zero for the derivative of Lyapunov function becoming negative that this fact guarantees stability of the system, so we have:

$$
\begin{aligned}
& -\mathrm{x} \tilde{\mathrm{x}}+\frac{1}{\beta_{1}} \mathrm{k}=0 \rightarrow \mathrm{k}=\beta_{1} \tilde{\mathrm{x} \tilde{\mathrm{x}}} \\
& -\tilde{\mathrm{x}}+\frac{1}{\beta_{2}} \bigcup_{\mathrm{dc}}=0 \rightarrow \mathrm{U}_{\mathrm{dc}}=\beta_{2} \tilde{\mathrm{x}}
\end{aligned}
$$

Unknown parameters of the system such as $R$ and $U_{d c}$ are estimated from the relations (9) and (10), respectively.

\subsection{Designing Sliding Mode Controller}

In sliding mode variable structure control, the switching function for the first order system is often defined as follows:

$$
\mathrm{S}=\mathrm{CX}
$$

where, $\mathrm{C}$ is the switching line factor, $\mathrm{X}$ is the system state variable. In the current tracker control, the state variable is normally selected like $X=$ i-iref. Sliding mode only appears at $X=$ 0 . Before reaching the $X$ state to the source, the system acts like a linear state feedback system, it means that the dynamic response of the system can not be pre-determined by the sliding mode dynamics and the stability of the system can not be guaranteed. So the swiching line, which has been defined by equation (11), is not suitable for the first order systems. For this reason, an integral term is introduced to follow the error in the switching function [23] and [24]. Thus, the switching function is designed as follows:

$$
S=X+c \int_{-\infty}^{t} X(\eta) d \eta
$$

The equation $\mathbf{S}=\hat{S}=0$ is as same as the equation $\dot{X}=-c \mathrm{X}$, that the solution is as follows:

$$
\mathrm{X}=\mathrm{X}_{0} \mathrm{e}^{-\mathrm{ct}}
$$

Equation (13) shows that the system state variables $\mathrm{X}$ with exponential function and constant time of $1 / \mathrm{c}$ becomes close to zero that implies sliding motion features, which can be pre-determined by the coefficient c. Considering the formula (13), it is also found that the dynamic response of integral sliding mode variable structure system integrator changes with an initial amount of integral term. The initial value of the integral term is selected as follows:

$$
\mathrm{h}_{0}=\int_{-s e}^{0} \mathrm{x}(\eta) \mathrm{d} \eta
$$

Thus, in order to guarantee the sliding mode input at the initial time must be $\left.\mathrm{S}\right|_{\mathrm{t}=0}=0$, the system must be $\mathrm{X}_{0}+\mathrm{ch}_{0}=0$, thus the following equation is obtained:

$$
\mathrm{h}_{0}=-\mathrm{X}_{0} / \mathrm{c}
$$

where, $X_{0}$ and $h_{0}$ are initial values of the state variable and the integral term, respectively. $\mathrm{X}_{0}$ initial value is always clear, VSC integrator is completely resistant. Thus, the switching function is selected as follows:

$$
S=X+c \int_{0}^{t} X(\eta) d \eta-X_{0}
$$

For current integrator VSC, state variable $\mathrm{X}$ is selected as an error vector between actual current and reference current in $\alpha \beta$ coordinate system. Selected switching function is defined as follows:

$$
\begin{aligned}
& S_{\alpha}=x_{\alpha}+c_{\alpha} \int_{0}^{t} x_{\alpha}(\eta) d \eta-x_{\alpha 0} \\
& S_{\beta}=x_{\beta}+c_{\beta} \int_{0}^{t} x_{\beta}(\eta) d \eta-x_{\beta 0}
\end{aligned}
$$

Where

$$
x_{\alpha}=i_{\alpha}-i_{\text {aref }}, \quad x_{\beta}=i_{\beta}-i_{\beta r e f}
$$

The equivalent control method is obtained based on the variable structure sliding mode 
control theory [25]. The equivalent control must be satisfied the following conditions:

$$
\mathrm{s}_{\alpha}=0, \mathrm{~s}_{\beta}=0
$$

Initial conditions are defined as follows:

$$
\mathrm{S}_{\alpha}=0, \mathrm{~S}_{\beta}=0
$$

With the help of two equations (2) and (17), the equivalent control is obtained in the following form:

$$
\begin{aligned}
& \mathrm{u}_{\text {tea }}=\mathrm{u}_{\alpha \alpha}-\mathrm{Ri}_{\alpha}+\mathrm{c}_{\alpha} \mathrm{Lx}_{\alpha}-\mathrm{Li}_{\text {arerf }} \\
& \mathrm{u}_{\mathrm{te \beta}}=\mathrm{u}_{s \beta}-\mathrm{Ri}_{\beta}+\mathrm{c}_{\beta} \mathrm{Lx}_{\beta}-\mathrm{Li}_{\beta \mathrm{rerf}}
\end{aligned}
$$

The switching control is defined as the following form:

$$
\begin{aligned}
& \Delta \mathrm{u}_{\mathrm{ta}}=\mathrm{K}_{\mathrm{a} 1} \mathrm{x}_{\mathrm{\alpha}}+\mathrm{K}_{\mathrm{a} 2} \\
& \Delta \mathrm{u}_{\mathrm{t} \beta}=\mathrm{K}_{\beta 1} \mathrm{x}_{\beta}+\mathrm{K}_{\beta 2}
\end{aligned}
$$

Based on the convergence conditions, $\mathrm{SS}^{*}<0$, the solution of inequality is obtained as follows:

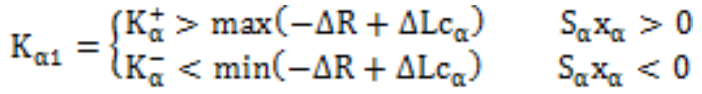

$$
\begin{aligned}
& \mathrm{K}_{\beta 1}= \begin{cases}\mathrm{K}_{\beta}^{+}>\max \left(-\Delta \mathrm{R}+\Delta \mathrm{L} \mathrm{c}_{\beta}\right) & \mathrm{S}_{\beta} \mathrm{x}_{\beta}>0 \\
\mathrm{~K}_{\beta}^{-}<\min \left(-\Delta \mathrm{R}+\Delta \mathrm{L} \mathrm{c}_{\beta}\right) & \mathrm{S}_{\beta} \mathrm{x}_{\beta}<0\end{cases} \\
& \mathrm{K}_{\mathrm{a} 2}=\left\{\begin{array}{l}
\mathrm{k}_{\mathrm{a} 2}^{+}>\max \left(\Delta \mathrm{U}_{\mathrm{sa}}-\Delta \mathrm{Ri}_{\mathrm{aref}}-\Delta \mathrm{Li}_{\mathrm{aref}}\right) \\
\mathrm{k}_{\mathrm{a} 2}^{-}<\min \left(\Delta \mathrm{U}_{\mathrm{a \omega}}-\Delta \mathrm{Ri}_{\mathrm{aref}}-\Delta \mathrm{Li}_{\text {aref }}\right)
\end{array}\right. \\
& \mathrm{K}_{\beta 2}=\left\{\begin{array}{l}
\mathrm{k}_{\beta 2}^{+}>\max \left(\Delta \mathrm{U}_{s \beta}-\Delta \mathrm{Ri}_{\beta \mathrm{ref}}-\Delta \mathrm{Li}_{\beta \mathrm{refe}}\right) \\
\mathrm{k}_{\beta 2}^{-}<\min \left(\Delta \mathrm{U}_{\bar{s} \beta}-\Delta \mathrm{Ri}_{\beta \mathrm{ref}}-\Delta \mathrm{Li}_{\beta \mathrm{ref}}\right)
\end{array}\right.
\end{aligned}
$$

In reviewing practical applications, the nonlinear components are spread with increasing the capacity of installed capacitor. On the other hand, transformer non-linear magnetic circuit may generate $\Delta \mathrm{L}$. On the other hand, the non-linear factors are created because of switching elements GTO / IGBT and diode is presented as $\Delta R$ [26]. Network voltage instability is expressed as $\Delta$ us. Above switching control can guarantee achieving the desired value.

The conditions, $\mathrm{SS}^{*}<0$, is in the nonlinear cases and external disturbances, so the system can achieve to the equivalent control slip level, stable performance, tracking current changes and being resistant.

\begin{tabular}{|c|c|c|}
\hline Value & Symbol & Quantity \\
\hline $0.15 \Omega$ & $\mathrm{R}$ & $\begin{array}{l}\text { Equivalent Resistance of } \\
\text { Inverter Losses }\end{array}$ \\
\hline $0.001 \mathrm{H}$ & $\mathrm{L}$ & Inductance \\
\hline $380 \mathrm{~V}$ & Us & Network Line Voltage \\
\hline $1.4 \Omega$ & $R 1$ & \multirow[t]{2}{*}{ Linear Load } \\
\hline $3.3 \mathrm{mH}$ & L1 & \\
\hline $8 \Omega$ & $R 2$ & \multirow[t]{2}{*}{ Non-linear Load of DC Side } \\
\hline $0.05 \mathrm{H}$ & $L 2$ & \\
\hline $5 \mathrm{KHz}$ & $f_{\mathrm{s}}$ & Switching Frequency \\
\hline 2 & $\beta_{1}$ & \multirow{2}{*}{ Observer Parameters } \\
\hline 500 & $\beta_{2}$ & \\
\hline
\end{tabular}

\section{Simulation Results}

The proposed control strategy has been simulated with a power system in MATLAB software. Simulation parameters (Fig. 1) has been given in Table 1, simulated non-linear load is an uncontrolled three-phase rectifier like a harmonic source.

Table (1): Parameters of Simulated System

As observed in formula (13), the values $c_{\alpha}$ $s_{\alpha}$ and $c_{\beta}$ indicate the dynamic implementation $s_{\alpha} \otimes f_{0}$ the system, which related with inverse of the electrical time constant.

$s_{\beta}>0$
$s_{\beta}<0 c_{\alpha}=\frac{p_{\alpha}}{\tau_{\theta}}=\frac{p_{\alpha} R}{L}, c_{\beta}=\frac{p_{\beta}}{\tau_{\theta}}=\frac{p_{\beta} R}{L}$

where, $p_{\alpha}$ and $p_{\beta}$ are positive constants, which determine the convergence speed of the control system response.

\subsection{Simulation Without Changing Parameters}


In this case, it is assumed that the system works with load 1 and at time $t=0.5 \mathrm{~s}$, load 3 suddenly enters to the circuit. The value of $c_{\alpha}$ and $c_{\beta}$ has been selected 6000 . The simulation results have been shown in Figure 2 .

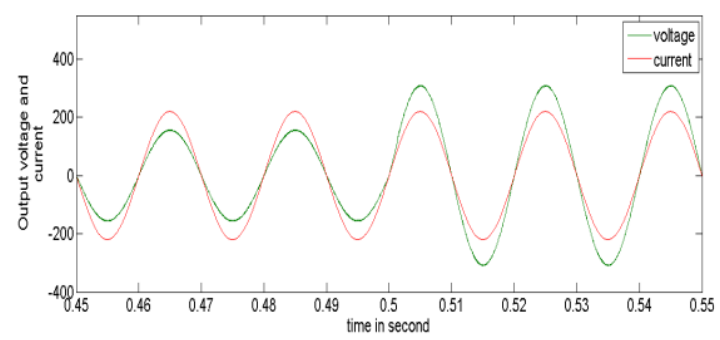

Figure (2): Results of the simulation without changing system parameters: one phase voltage and source current

Figure (2) shows that after putting DSTATCOM in the circuit, reactive power is compensated and sensitive loads current embedded in the circuit are controlled with high speed and accuracy.

\subsection{Simulation Under Change In Parameters}

In this case, the load 1 enters the circuit at the time $\mathrm{t}=0.5 \mathrm{~s} . c_{\alpha}=c_{\beta}=0$ is selected. The system parameters change domain has been stated in the following:

$$
-\odot 0.15 \Omega \odot \leq \odot \Delta R \quad \leq \odot 0.15 \Omega, \quad-\odot 0.001 H \quad \leq \odot \Delta L
$$
$\leq \odot 0.001 \mathrm{H}$

To investigate the switching control performance under parameters disturbances, the system performance has been shown in Figure 3. $k \alpha 1=k \beta 1=5$ and $k \alpha 2=k \beta 2=0.1$ have been selected. As can be seen in Figure (3), the controller shows an appropriate response to follow the reference signal and also shows an effective and ideal compensation.
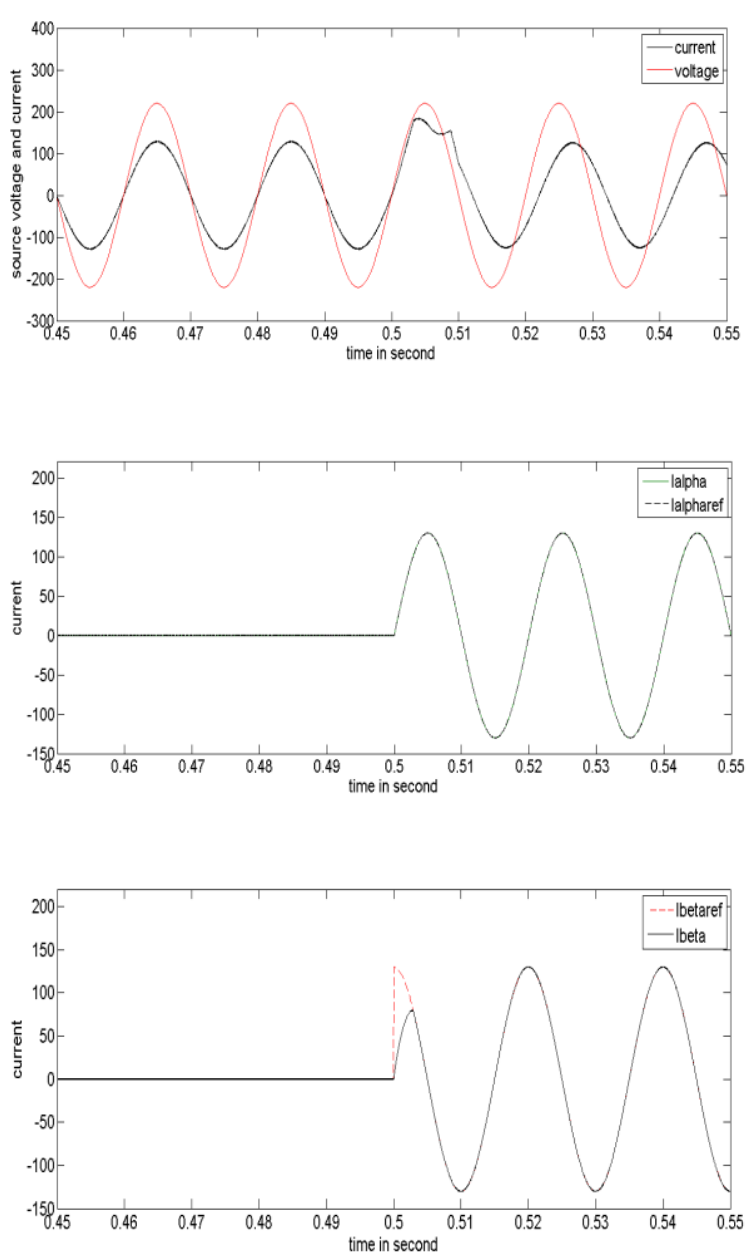

Figure (3): The results of simulation under parameters disturbances: voltage $u_{s a}$ and source current $i_{s a}$, following components $\beta \alpha$

\subsection{Effect of Factors $c_{\alpha}$ and $c_{\beta}$ on Performance of System Under Parameter Disturbance}

Disturbance domain of system parameters is as same as the previous section. In order to investigate the effect of disturbance of $c_{\alpha}$ and $c_{\beta}$ on system performance, values of $c_{\alpha}$ and $c_{\beta}$ up to 6000 are increased without switching control, for example $k \alpha 1=k \beta 1=k \alpha 2=k \beta 2=0$. Compensator control under load 1 has started at time $t=0.5 \mathrm{~s}$. The simulation results have been shown in Figure (4), it is observed that the control system accurately follows the reference compensator current and also keeps voltage and reference current at a same phase. 


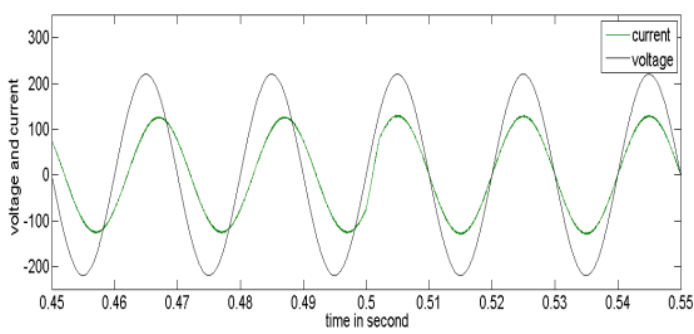

Figure (4): The results of simulation under load 1: voltage $u_{s a}$ and source current $i_{s a}$

From the simulation results of section 1 and 2, it can be concluded that when the system parameter disturbance occurs in the system parameter, introducing of the system switching control is created in such a way that compensator current correctly follows the reference. In addition, the system can only use the equivalent control and achieves to a good result for tracker by adjusting $c_{\alpha}$ and $c_{\beta}$ values. Therefore, the capacity is in permitted limit for DSTATCOM, if the control method initially guarantees the entry of sliding mode level system, the controller can only consist of the equivalent control part that causes the system not acting only in steady state, but reduces the complexity of the controller.

However, with the increase in equipment capacity, if only equivalent control is used, the condition of sliding mode system $S \dot{S}<0$ does not always hold, for example, s-value may not go towards zero, and in this case, the switching control is required.

\section{Conclusion}

Indirect adaptive sliding mode variable structure control method is for the DSTATCOM state model coupled in $\alpha \beta$ rotating coordinate system, which proposed observer has been used to estimate the resistance unknown parameters and DC link. This controlling method causes the system enters quickly to the sliding mode at first and compensates the reactive power. The controller under sudden load changes shows a quick dynamic response and is resistant to disturbances parameters.

\section{References}

Bollen, Math HJ, Mats Hager, and Christian Roxenius. "Effect of induction motors and other loads on voltage dips: theory and measurements." In Power Tech Conference Proceedings, 2003 IEEE Bologna, vol. 3, pp. 6pp. IEEE, 2003.

Tayjasanant, Thavatchai, Wencong Wang, Chun $\mathrm{Li}$, and Wilsun $\mathrm{Xu}$. "Interharmonic-flicker curves." Power Delivery, IEEE Transactions on 20, no. 2 (2005): 1017-1024.

Elnady, Amr, and Magdy MA Salama. "Unified approach for mitigating voltage sag and voltage flicker using the DSTATCOM." Power Delivery, IEEE Transactions on 20, no. 2 (2005): 992-1000.

Gomez, J. C., M. M. Morcos, C. Reineri, and G. Campetelli. "Induction motor behavior under short interruptions and voltage sags." Power Engineering Review, IEEE 21, no. 2 (2001): 1115.

Shivkumar I, Ghosh A, Joshi A " Multilevel Inverter topologies for D-Statcom application" Electric power system Research, Vol 75, Issues 2-3, August 2012, p.p. 161-170.

Liu Wenhua, Liu Bing, Wang Zhi-yong. “ $\pm 100 \mathrm{kvar}$ D-STATCOM Based on IGBT Three-level Inverter," Automation of Electrical Power Systems) , 2002, 26(1) : 70$73,77$.

Jia Jiabin, Yuan Jiaxin, Jiang Fangfang et al. "Optimized Controlling of the Distribution Static Synchronous Compensator Based on Quasi-Sliding Mode," High Voltage Engineering, 2004, 30(8):50-55.

Zhou Weiping, $\mathrm{Wu}$ Zhengguo, Xia $\mathrm{Li}$ et al. "A current tracking performance optimization control method in three-phase three-wire active power filter," Proceedings of the CSEE, 2004, 24(11) : 85- 90.

Luowei Zhou and Zichang Li. "A novel active power filter based on the least compensation current control method," IEEE trans Power Electron. 2000, 15(4) : 655-659.

D.Biel, EFossas, F.Guinfoan, EAlarcon, and APoveda, -Application of sliding-mode control to the design of a buck-based 
sinusoidal generatorll. IEEE Trans. on Induswial Electronics, Vo1.48, pp.563-57 I, June, 2001.

Bhim Singh and Jitendra Solanki, "A comparison of control algorithms for DSTATCOM," IEEE Transactions on Industrial Electronics, vol. 56, no. 7, pp. 2738-2745, July 2009.

G. Bhuvaneswari and M.G Nair, "Design, simulation, and analog circuit implementation of a three-phase shunt active filter using I $\cos \varnothing$ algorithm," IEEE Trans. Power Deliv, vol. 23, no. 2, pp. 1222-1235, 2008.

M.A Eldery, E.F. El-Saadany and M.M.A. Salama, "Sliding Mode Controller for Pulse Width Modulation Based DSTATCOM," in Proc. Of CCECE, 2006, pp.2216-2219.

V.S. Bandal and P.N. Madurwar, "Performance analysis of shunt active power filter using sliding mode control strategies," on 12th International Workshop Variable Structure Systems (VSS), 2012, pp.214-219.

B. Singh, K. Al-Haddad and A. Chandra, "Active power filter with sliding mode control," IEE Proc.,Generation, Transmission and Distribution, vol.144, no.6, pp.564-568, Nov 1997.

R. R. Errabelli, Y.Y. Kolhatkar and S.P. Das, "Experimental investigation of sliding mode control of inverter for custom power applications," Power Engineering Society General Meeting, 2006, pp.8- 16.

M. Teodorescu, D. Stanciu, C. Radoi and S.G. Rosu, "Implementation of a three-phase active power filter with sliding mode control," in Proc. Of IEEE International Conference on Automation Quality and Testing Robotics (AQTR), 2012, pp.9-13.

N. Mendalek, K. Al-Haddad, H.Y. Kanaan and G. Hassoun, "Sliding mode control of threephase four-leg shunt active power filter," in Proc. of IEEE Power Electronics Specialists Conference, PESC, 2008, pp.4362-4367.

S. Saetio, R. Devaraj, and D.A. Torrey, "The design and implementation of a three-phase active power filter based on sliding mode control", IEEE Trans. Ind. Appl., pp. 993-1000, 1995.
Han Yingduo, Yan Ganguz, Jiang Qlrong et al. "Electric power in information society and FACTS \& DFACTS, "Automation of Electric Power Systems, 2000, 24(19) : 1-7

Wang Zhaoan. "Harmonics suppression and reactive power compens ation," Beijing: China Machine Press, 1998.

WeiWen-hui, Liu Wen-hua, Song Qiang. "Research on fast dynamic control of static synchronous Compensator using cascade

multilevel inverters," Proceedings of the CSEE,2005,25(3):23-28

Se-Kyo Chung, Jung-Hoon Lee, Jong-Sun KO, et al. "A Robust Speed Control of Brushless Direct Drive Motor Using Integral Variable Structure Control with Sliding Mode Observer," IEE Proceedings - Electric Power Applications ,November 1995 ,Volume 142, Issue 6: p. 361-370.

GuanCheng , Zhu Shan-an. "Derivative and integral sliding mode adaptive control for a class of nonline arsystem and its application to an electro-hydraulic servo system," Proceedings of the CSEE, 2005 ,25(4):103-108.

Gao Weibing. "Theory and design method of sliding mode variable structure," Beijing: Science Press,1998.

JIANG Qirong, JIANG Xia, LIANG Xu, CHEN Xueyu. "Nonlinear characteristics of a large capacity STATCOM, "Journal of Tsinghua University(Science and Technology, 2003, 1 (43) : 326-328.

M Habibi, M Ghane, AB Novinzadeh, Modeling Integrative and Derivative Systems in Bond Graph Modeling and using it in Adaptive Control, Life Science Journal 10 (8s) 